\title{
Selection and Experimentation of the Best Hybrid Green Composite Using Advanced MCDM Methods for Clean Sustainable Energy Recovery: A Novel Approach
}

\author{
Soutrik Bose \\ Department of Mechanical Engineering, \\ MCKV Institute of Engineering, 243 G.T. Road (N), \\ Liluah, Howrah, 711204, West Bengal, India. \\ Corresponding author: soutrikboseju@gmail.com \\ Nabankur Mandal \\ Department of Mechanical Engineering, \\ MCKV Institute of Engineering, 243 G.T. Road (N), \\ Liluah, Howrah, 711204, West Bengal, India. \\ E-mail: nabankur2009@gmail.com \\ Titas Nandi \\ Department of Mechanical Engineering, \\ Jadavpur University, Kolkata, 700032, West Bengal, India. \\ E-mail: titas_nandi@yahoo.in
}

(Received November 26, 2018; Accepted December 23, 2019)

\begin{abstract}
Relevant and appropriate selection of best hybrid material is a challenging task for the recent industries. The mandatory criterion is to deal with the enhanced productivity with minimum cost. Therefore, this paper highlights on the comparative study between the advanced multi-criteria approaches namely ARAS, MABAC, COPRAS and MOOSRA methods for the selection of the best hybrid composite material using aluminum ( $\mathrm{Al})$ as base material varying different reinforcement weights and recycling with various industrial wastes by stir casting. Al/WCE gives superior tribomechanical properties at lower cost than any other reinforcements. These advanced MCDM methods are applied, based on the properties and attributes of the hybrid composites, to compare between the computational and experimental results. The results exactly corroborate with the previous research results, which authenticate the expediency of these methods during the solving of complex hybrid material selection problems for sustainable energy recovery. Out of 48 different samples, A30 is obtained to be the best sample by ARAS approach (rank 1) which is $\mathrm{Al}+\mathrm{Al}_{2} \mathrm{O}_{3}$ at $12.5 \%$ wt. addition. A24 is ranked 2 which is heat treated $12.5 \%$ wt. WCE. But the same A30 is obtained to be rank 5 and A24 is obtained to be rank 1 by MABAC method, A30 is obtained to be rank 2 and A24 to be rank 1 by COPRAS method, and A30 is calculated to be rank 1 and A24 to be rank 11 by MOOSRA method. A24 is also obtained to be the best hybrid composite as per the experimentation. This paper also aims for proper recovering of environmental friendly renewable energy for the society by fabricating the best hybrid green composite for sustainable development.
\end{abstract}

Keywords- ARAS, MABAC, COPRAS, MOOSRA, Energy recovery.

\section{Introduction}

Recent manufacturing and design industries are always on the search for innovative hybrid novel composites for better performance of the product with minimum investment thus, increasing the profit margin. Proper techniques and criteria are necessary for obtaining the best material in an adroit method of material selection, which depends on increasing the efficiency, reducing the 
International Journal of Mathematical, Engineering and Management Sciences

Vol. 5, No. 3, 556-566, 2020

https://doi.org/10.33889/IJMEMS.2020.5.3.046

overall cost and achieving high performance of the product. Inapt material selection escorts to immature failure of the products leading to very high cost (Chatterjee and Chakraborty, 2013). Therefore, appropriate prediction, detection and selection of pertinent material with specific functionality to attain the most excellent product with elevated performance and least cost is the most vital criteria. The physical, chemical, metallurgical and tribomechanical properties are the prime concern, which is graphically discussed later in this paper. Therefore, four advanced MCDM approaches, like ARAS (Zavadskas and Turskis, 2010; Chatterjee and Chakraborty, 2013), MABAC (Pamucar and Cirovic, 2015; Xue et al., 2016; Biswas and Das, 2018), COPRAS (Chatterjee et al., 2011; Maity et al., 2012; Popovic et al., 2012) and MOOSRA (Sarkar et al., 2015; Adali and Isik, 2017) supported by a number of strong mathematical foundations, are therefore proposed for the incorporation of the scopes and objectives of producing the best hybrid material in design arena and manufacturing industries. But the performance of the material may gets compromised under sundry conditions and can further deviate from the probable result which has to be optimized to obtain the best result. (Hassan and Aigbodion, 2015) showed that indecent wettability is created on the facade of the molten metal by the formation of different oxides of contaminants, and hence the addition of hybrid reinforcements is an essential factor. Wettability can be improved if the interfacial bonding is strong enough. Improved tribomechanical qualities were achieved with superior percentage of weights of WCE than ES (Hassan and Aigbodion, 2015). Deep et al. (2016) investigated on different composites of aluminum reinforced with silicon carbide varying the weight percentages and inferred enhanced mechanical properties with increments of reinforcements. After going through all the literatures, the main gaps are identified that very few research works have been carried out on ES and WCE based green MMC. It is also identified that very few novel methods are proposed to fabricate green hybrid MMC reinforcing with $\mathrm{SiC}, \mathrm{SiC}+\mathrm{SSA}, \mathrm{CDA}$ and $\mathrm{B}_{4} \mathrm{C}$. The most important goal of this manuscript is to inspect the probability to develop better hybrid green composite through stir casting route by recycling these hazardous wastes.

\section{Nomenclature}

\begin{tabular}{|c|c|c|c|}
\hline ARAS & Additive ratio assessment & MCDM & Multi-criteria decision making \\
\hline MABAC & $\begin{array}{l}\text { Multi-attributive border approximation } \\
\text { area comparison }\end{array}$ & ES & Eggshells \\
\hline COPRAS & Complex proportional assessment & MMC & Metal-matrix composites \\
\hline MOOSRA & $\begin{array}{l}\text { Multiple-objective optimization of } \\
\text { simple ratio analysis }\end{array}$ & $\mathrm{SiC}$ & Silicon carbide \\
\hline $\mathrm{Al} / \mathrm{WCE}$ & $\begin{array}{l}\text { Aluminum reinforced with waste } \\
\text { carbonized eggshells }\end{array}$ & $\mathrm{SiC}+\mathrm{SSA}$ & $\begin{array}{l}\text { Silicon carbide with snail-shell } \\
\text { ash }\end{array}$ \\
\hline $\mathrm{Al}+\mathrm{Al}_{2} \mathrm{O}_{3}$ & Aluminum reinforced with alumina & $\mathrm{CDA}$ & Cow-dung ash \\
\hline HT & Heat treated & $\mathrm{B}_{4} \mathrm{C}$ & Boron carbide \\
\hline
\end{tabular}


International Journal of Mathematical, Engineering and Management Sciences

Vol. 5, No. 3, 556-566, 2020

https://doi.org/10.33889/IJMEMS.2020.5.3.046

\section{ARAS}

ARAS method is the perceptible method of calculations depending on the utility theory, which relates with the relative efficiency of diverse alternatives. This value is unswervingly depends on the comparative result of the weighted stricture of the decisive factors. Table 1 below shows the nomenclature and criteria of the 48 composite materials selected for ARAS and MABAC. The sequential steps of ARAS method are:

Step 1: An explicit normalization procedure is projected for the beneficial attributes $X_{i j}$ and the reciprocal of it is referred to be non-beneficial attributes $X_{i j}$. Therefore, the normalized decision matrix is computed as:

$$
X_{i j}=\frac{1}{X_{i j}}
$$

Step 2: The normalized matrix $R$ is determined:

$$
R=\left[r_{i j}\right]_{p x q}=\frac{X_{i j^{\prime}}}{\sum_{i=1}^{p} X_{i j^{\prime}}}
$$

The weighted-normalization of the decision matrix $D$ is determined:

$$
D=\left[Y_{i j}\right]_{p x q}=r_{i j} x w_{j}(i=1 \text { to } p ; j=1 \text { to } q)
$$

where, $w$ signifies criteria weights.

Step 3: The function of optimality $S_{i}$ is then calculated as:

$S_{i}=\sum_{j=1}^{q} Y_{i j}$

Depending on the higher $S_{i}$ value, better alternative is obtained, which is directly proportional to $D$ and $w$.

Step 4: $U_{i}$ stands for utility degree is then computed for all the alternatives and compared with the maximum efficient alternative $S_{o}$ which is given below:

$$
U_{i}=\frac{S_{i}}{S_{o}}
$$

Table 1. Nomenclature of the criteria

\begin{tabular}{|l|c|c|c|}
\hline Criteria & Abbreviation & Beneficial & Non-beneficial \\
\hline Hardness (BHN) & HN & HN & PO \\
\hline Tensile strength (MPa) & TS & TS & DC \\
\hline Fatigue strength (MPa) & FS & FS & \\
\hline Porosity & PO & & \\
\hline Corrosion Rate (mm/year) & CR & & \\
\hline Ductility & DC & & \\
\hline
\end{tabular}


International Journal of Mathematical, Engineering and Management Sciences

Vol. 5, No. 3, 556-566, 2020

https://doi.org/10.33889/IJMEMS.2020.5.3.046

Table 2. Nomenclature of hybrid MMC

\begin{tabular}{|c|c|c|c|c|c|c|c|}
\hline Material & Mat. No. & Material & Mat. No. & Material & Mat. No. & Material & Mat. No. \\
\hline ES $(0)$ & $\mathrm{A} 1$ & WCE (0) & $\mathrm{A} 13$ & Alumina (0) & A25 & $\mathrm{SiC}(0)$ & A37 \\
\hline ES (2.5) & $\mathrm{A} 2$ & WCE (2.5) & A14 & $\mathrm{Al}_{2} \mathrm{O}_{3}(2.5)$ & A26 & $\mathrm{SiC}(2.5)$ & A38 \\
\hline ES (5) & A3 & WCE (5) & A15 & $\mathrm{Al}_{2} \mathrm{O}_{3}(5)$ & A27 & $\mathrm{SiC}(5)$ & A39 \\
\hline ES (7.5) & A4 & WCE (7.5) & A16 & $\mathrm{Al}_{2} \mathrm{O}_{3}(7.5)$ & A28 & $\operatorname{SiC}(7.5)$ & $\mathrm{A} 40$ \\
\hline ES (10) & A5 & WCE (10) & A17 & $\mathrm{Al}_{2} \mathrm{O}_{3}(10)$ & A29 & $\mathrm{SiC}(10)$ & A41 \\
\hline ES (12.5) & A6 & WCE (12.5) & A18 & $\mathrm{Al}_{2} \mathrm{O}_{3}(12.5)$ & $\mathrm{A} 30$ & $\mathrm{SiC}(12.5)$ & A42 \\
\hline ES-HT (0) & A7 & WCE-HT (0) & A19 & $\mathrm{Al}+\mathrm{B}_{4} \mathrm{C}(0)$ & $\mathrm{A} 31$ & $\mathrm{CDA}(0)$ & A43 \\
\hline ES-HT(2.5) & A8 & WCE-HT (2.5) & A 20 & $\mathrm{Al}+\mathrm{B}_{4} \mathrm{C}(2.5)$ & A 32 & $\operatorname{CDA}(2.5)$ & A44 \\
\hline ES-HT (5) & A9 & WCE-HT (5) & A 21 & $\mathrm{Al}+\mathrm{B}_{4} \mathrm{C}(5)$ & A33 & $\mathrm{CDA}(5)$ & A 45 \\
\hline ES-HT(7.5) & A10 & WCE-HT (7.5) & A22 & $\mathrm{Al}+\mathrm{B}_{4} \mathrm{C}(7.5)$ & A34 & $\operatorname{CDA}(7.5)$ & A46 \\
\hline ES-HT (10) & A11 & WCE -HT(10) & $\mathrm{A} 23$ & $\mathrm{Al}+\mathrm{B}_{4} \mathrm{C}(10)$ & A35 & $\mathrm{CDA}(10)$ & A47 \\
\hline ES-HT(12.5) & A12 & WCE-HT (12.5) & A24 & $\mathrm{Al}+\mathrm{B}_{4} \mathrm{C}(12.5)$ & A36 & $\operatorname{CDA}(12.5)$ & A 48 \\
\hline
\end{tabular}

There is a variation of the utility degree from $0-100 \%, U_{\max }$ represents the best preference amongst all the alternatives and therefore ranking is given in accordance with the highest preference. From this ARAS method, A30 is ranked 1 and A24 is ranked 2 as highlighted in Figure 1. WCE at a temperature of $750^{\circ} \mathrm{C}$, melted in a crucible furnace, then cooled around $600^{\circ} \mathrm{C}$ and manually stirred for 5 minutes in the stir casting route. Table 2 represents the nomenclature of the 48 hybrid MMC samples.

\section{MABAC}

MABAC is incorporated after acquiring the weight coefficients. The key computational formulation of this method is to obtain the border approximation area (BAA) and its distance. Following are the required steps:

Step 1: At first the primary decision matrix $X=\left[x_{i j}\right]_{p x q}$ is formed.

Step 2: Then the ultimate decision matrix $N=\left[n_{i j}\right]_{p x q}$ is normalized. The rudiments are:

(a) Regarding the Beneficial criteria an upper value is preferable:

$n_{i j}=\frac{x_{i j}-x_{i-}}{x_{i_{+}}-x_{i_{-}}}$

(b) Regarding the Cost criteria a lower assessment of the rudiments is preferable:

$n_{i j}=\frac{x_{i j}-x_{i+}}{x_{i-}-x_{i+}}$

Step 3: Then the weighted-normalized decision matrix $V$ is calculated:

$V=v_{i j}=w_{i \cdot}\left(n_{i j}+1\right)$ 
International Journal of Mathematical, Engineering and Management Sciences

Vol. 5, No. 3, 556-566, 2020

https://doi.org/10.33889/IJMEMS.2020.5.3.046

Step 4: The border approximation area matrix $G$ is hence calculated by following equation:

$$
g_{i}=\left(\prod_{j=1}^{p} v_{i j}\right) \frac{1}{p^{\prime}}
$$

where, $v_{i j}$ and $p^{\prime}$ the rudiments and total alternatives. Then $G=\left[\begin{array}{llll}g_{1} & g_{2} & \ldots \ldots \ldots \ldots & g_{q}\end{array}\right]$ is obtained.

Step 5: $Z$ which is the distance from BAA is calculated:

$Z=V-G$

$G$ is dividing the entire approximation area into two halves as higher approximated area $G^{+}$and lower approximated area $G^{-}$. Alternative $A_{i}$ belongs to BAA $G$ or either of the upper and lower approximation area based on following equation:

$$
A_{i} \in\left\{\begin{array}{l}
G^{+} ; \text {if } z_{i j}>1 \\
G^{+} ; \text {if } z_{i j}=0 \\
G^{-} ; \text {if } z_{i j}<1
\end{array}\right\}
$$

Step 6: The overall score of the alternatives is computed by:

$$
S_{i}=\sum_{j=1}^{q} z_{i j}
$$

Ranking is done depending on the descending value of $S_{i}$. A30 is obtained to be rank 5 and A24 is obtained to be rank 1 as depicted in Figure 1.

\section{COPRAS}

COPRAS provide direct proportional criteria and ranking order depending on the utility factors. Both positive (beneficial) and negative (non-beneficial) criteria are appraised separately as given in Table 1. The steps are shown below:

Step 1: The decision matrix is normalized to acquire dimensionless values of dissimilar criteria.

Step 2: Then $D$ is determined.

$$
D=\left[Y_{i j}\right]_{p x q}=r_{i j} x w_{j}(i=1 \text { to } p ; j=1 \text { to } q)
$$

Then, the summation of all weighted normalized values (dimensionless) $Y_{i j}$ of each criterion identical to its weight is determined.

$$
\sum_{i=1}^{m} Y_{i j}=w_{j}
$$


International Journal of Mathematical, Engineering and Management Sciences

Vol. 5, No. 3, 556-566, 2020

https://doi.org/10.33889/IJMEMS.2020.5.3.046

Step 3: The summations of $Y_{i j}$ are computed for all the attributes using the following equations:

$$
\begin{aligned}
& S_{i+}=\sum_{j=1}^{q} Y_{+i j} \\
& S_{i-}=\sum_{j=1}^{q} Y_{-i j}
\end{aligned}
$$

Enhanced the value of $S_{i+}$ and lower the value of $S_{i-}$, better the alternatives are articulated by the following equations:

$$
\begin{aligned}
& S_{+}=\sum_{i=1}^{p} S_{i+}=\sum_{i=1}^{p} \sum_{j=1}^{q} Y_{+i j} \\
& S_{-}=\sum_{i=1}^{p} S_{i-}=\sum_{i=1}^{p} \sum_{j=1}^{q} Y_{-i j}
\end{aligned}
$$

Step 4: After determining the significances, the priorities $Q_{i}$ are calculated below:

$$
Q_{i}=S_{i+}+\frac{S_{\text {min- }} \sum_{i=1}^{p} S_{i-}}{S_{i-} \sum_{i=1}^{p} \frac{S_{\min -}}{S_{i-}}}
$$

where $S_{\text {min- }}$ is the minimum value of $S_{i-}$. When $Q_{i}$ is enhanced, then the priority of the alternative is also higher. $Q_{\max }$ is the best selection termed as maximum relative significance.

Step 5: Then the perceptible utility $U_{i}$ are obtained as follows:

$U_{i}=\left[\frac{Q_{i}}{Q_{\max }}\right] \times 100 \%$

where $Q_{\max }$ signifies the maximum value of relative significance. COPRAS directly evaluate the proportional dependencies of significances and utility degrees of the alternatives. Here, A24 is again obtained to be rank 1 but A30 is found to be rank 2 as highlighted in Figure 1.

\section{MOOSRA}

In MOOSRA identification of a set of optimal trade-off solutions between the conflicting criteria is the most important task for better understanding of the problem to select the best conciliation. Hence, this method is an appropriate tool for ranking the alternatives based on compound conflicting attributes. The steps are:

Step 1: The decision matrix is normalized.

$$
x_{i j}=\left[\begin{array}{cccc}
x_{11} & x_{12} & \ldots . . & x_{1 r} \\
x_{21} & x_{22} & \ldots . . & x_{2 r} \\
\ldots . . & \ldots . . & \ldots . . & \ldots . . \\
x_{s 1} & x_{s 2} & \ldots . . & x_{s r}
\end{array}\right]
$$


International Journal of Mathematical, Engineering and Management Sciences

Vol. 5, No. 3, 556-566, 2020

https://doi.org/10.33889/IJMEMS.2020.5.3.046

Step 2: The normalized elements of the fuzzy decision matrix are calculated using this equation:

$$
x_{i j}^{*}=\frac{x_{i j}}{\sqrt{\sum_{i=1}^{r} x_{i j}^{2}}}
$$

where, $x_{i j}^{*}$ is the normalized performance of $i^{\text {th }}$ alternative on $j^{\text {th }}$ objective for $i=1$ to $r$ and $j=1$ to $s$.

Step 3: The performance of the alternatives is determined. $y_{i}$ is the performance score calculated by:

$$
y_{i}=\frac{\sum_{j=1}^{p} \lambda_{j} x_{i j}^{*}}{\sum_{j=p+1}^{r} \lambda_{j} x_{i j}^{*}}
$$

where, $p$ represents attributes, $\lambda_{j}$ is the associated weight of the $j^{\text {th }}$ attributes. Ranking is obtained by the overall performance score of each alternative $y_{i}$. In this method, A30 is obtained as rank 1 but A24 is calculated to be rank 11 as depicted by the Figure 1.

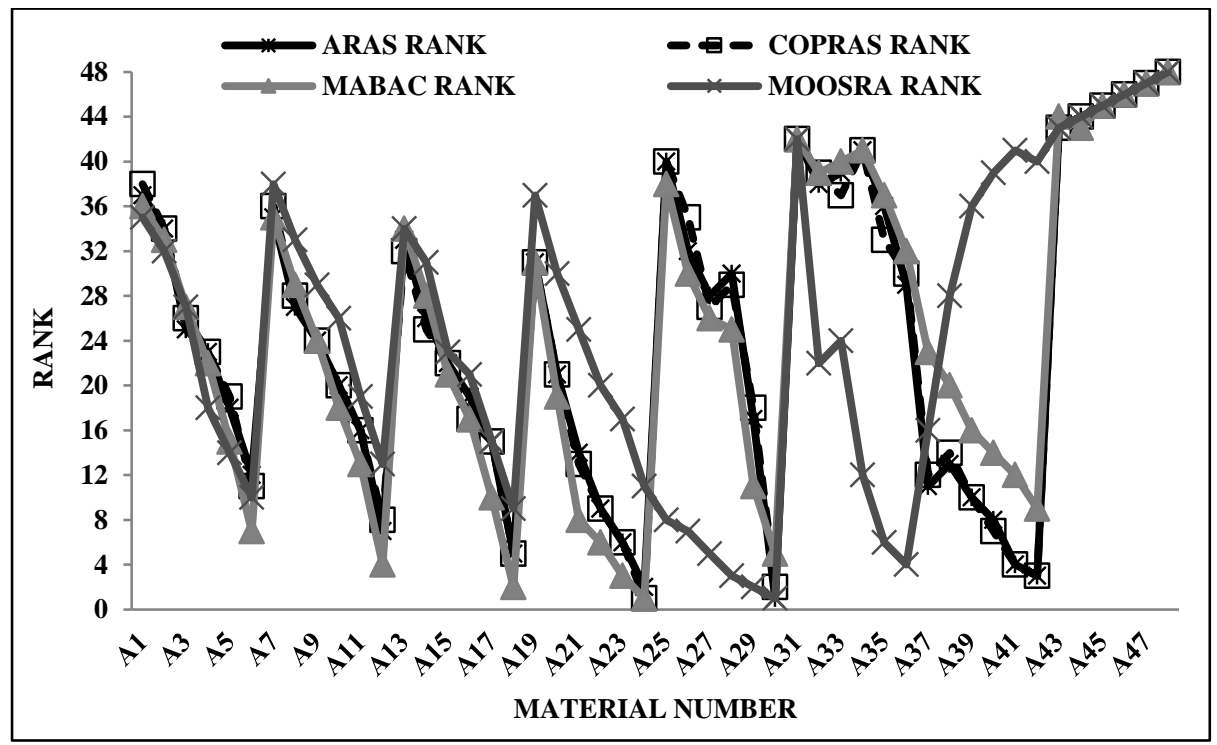

Figure 1. Rank of hybrid green composite used for energy recovery 
International Journal of Mathematical, Engineering and Management Sciences

Vol. 5, No. 3, 556-566, 2020

https://doi.org/10.33889/IJMEMS.2020.5.3.046

\section{Discussion}

The mandatory element is to select proper green materials / suppliers. The other important elements are proper collection centers installation for collecting the disposals, recycling and reuse for better designing of green manufactured product, use of environment friendly technology, pollution control, green packaging and pollution control management system. Therefore, evaluation of the recovered energy with a scope of environmental sustainability should be done considering multiple scenarios based on multiple criteria. This paper gives a clear view on the recycling of industrial waste like eggshells for clean sustainable energy recovery and for an ecofriendly society at large. Waste eggshells and carbon contents are extremely hazardous, so it is a mandatory task to recycle and reuse these hazardous contaminants for a sustainable energy development. This paper proposes a sustainable way of energy recovery from the fabrication of harmful waste carbonized eggshells and correlating with the MCDM and experimental results. Figure 2 represents the dependency and comparative analysis of mechanical properties on the reinforcement weight percentage on 25 fabricated samples of ES and WCE. Table 3 depicts the nomenclature and the composition of the $\mathrm{Al}$ with the difference weight percentage of the reinforcements. Percentage of weight is considered in the experimental methodology because the percentage is taken according to $100 \mathrm{gm}$ weight of the powdered samples which is much easier to calculate and use for fabrication purpose. Also, in case of volume percentage approach density needs to be calculated with respect to time as the hybrid composite developed is porous and prone to moisture which is very tedious approach. The impurities and the harmful contaminants present in the atmosphere are highly prone to react with the composite hampering the interfacial bonding between $\mathrm{Al}$ and the reinforcements, therefore the reinforcements are pre-heated to a temperature about $300^{\circ} \mathrm{C}$ before adding to the crucible and then the composite mixture is continuously stirred in the crucible (Bose et al., 2018). From the advanced MCDM techniques it is very much clear that the ES and WCE are the best developed hybrid composite which is feasible for environmental sustainability, hence from the 48 MCDM hybrid composites as shown in Table 2, 25 feasible environmental friendly samples are prepared varying the different weight percentages as shown in the Table 3 . The brittleness reduces the toughness and ductility. $\mathrm{Al}+\mathrm{Al}_{2} \mathrm{O}_{3}$ sample provides reduced toughness with the occurrence of brittle failure. Sample number 3 is obtained to be the best sample after all the experiments and hence the optimum result is reached. The best result of tensile strength is $274 \mathrm{MPa}$ and $295 \mathrm{MPa}$ for ES and WCE whereas the fatigue strength is $135 \mathrm{MPa}$ and $151 \mathrm{MPa}$ in ES and WCE, respectively. (Bose et al., 2019) obtained the best hybrid green composite by recycling waste carbonized eggshells which are proved to be better reinforcements than $\mathrm{SiC}+\mathrm{SSA}$ at higher weights. Initially the cost of the aluminum was approximately INR 300. Eggshells are almost available at every household waste, so no investments were done on it. The processing cost of WCE with the carbon powders obtained to be only INR 263 whereas for SiC+SSA accounted for INR 278 which is costlier than that of WCE at $12.5 \mathrm{wt} . \%$ as shown in the Figure 3. 
International Journal of Mathematical, Engineering and Management Sciences

Vol. 5, No. 3, 556-566, 2020

https://doi.org/10.33889/IJMEMS.2020.5.3.046

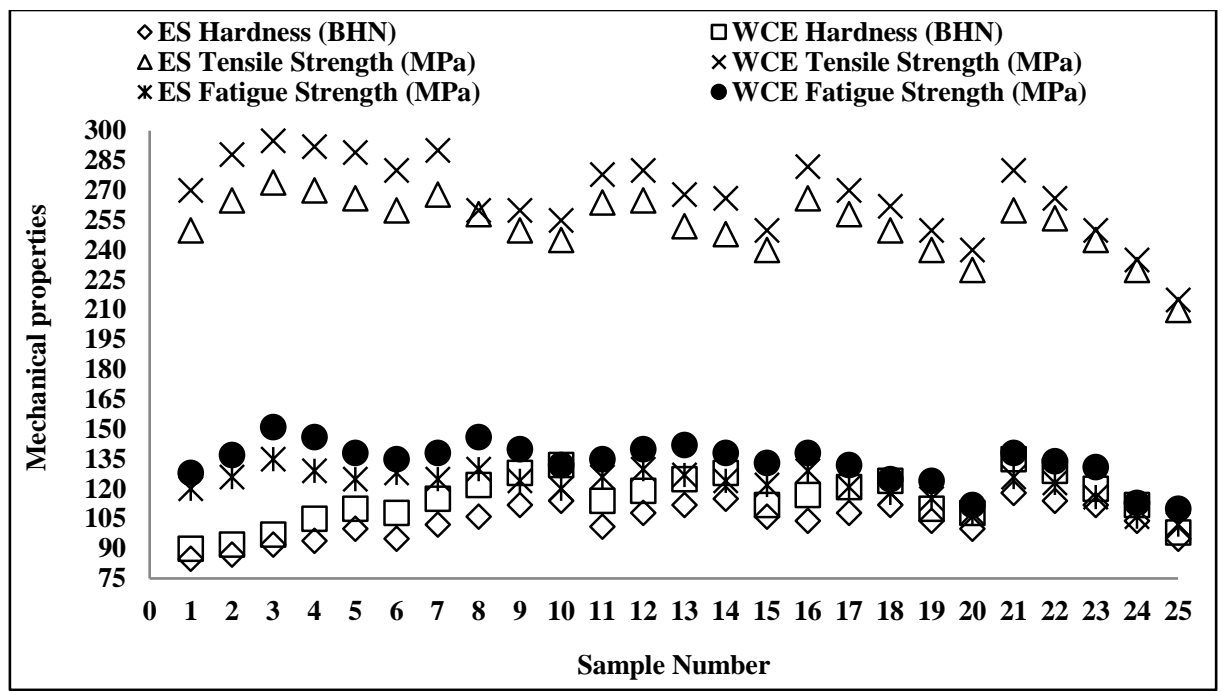

Figure 2. Variation of mechanical properties of different hybrid composites

Table 3. Nomenclature and wt.\% of the fabricated samples for experiments

\begin{tabular}{|c|c|c|c|c|c|c|c|c|}
\hline Sample & $\mathrm{SiC}$ & ES/WCE & Sample & $\mathrm{SiC}$ & ES/WCE & Sample & $\mathrm{SiC}$ & ES/WCE \\
\hline 1 & 2.5 & 2.5 & 10 & 5 & 12.5 & 19 & 10 & 10 \\
\hline 2 & 2.5 & 5 & 11 & 7.5 & 2.5 & 20 & 10 & 12.5 \\
\hline 3 & 2.5 & 7.5 & 12 & 7.5 & 5 & 21 & 12.5 & 2.5 \\
\hline 4 & 2.5 & 10 & 13 & 7.5 & 7.5 & 22 & 12.5 & 5 \\
\hline 5 & 2.5 & 12.5 & 14 & 7.5 & 10 & 23 & 12.5 & 7.5 \\
\hline 6 & 5 & 2.5 & 15 & 7.5 & 12.5 & 24 & 12.5 & 10 \\
\hline 7 & 5 & 5 & 16 & 10 & 2.5 & 25 & 12.5 & 12.5 \\
\hline 8 & 5 & 7.5 & 17 & 10 & 5 & & & \\
\hline 9 & 5 & 10 & 18 & 10 & 7.5 & & & \\
\hline
\end{tabular}

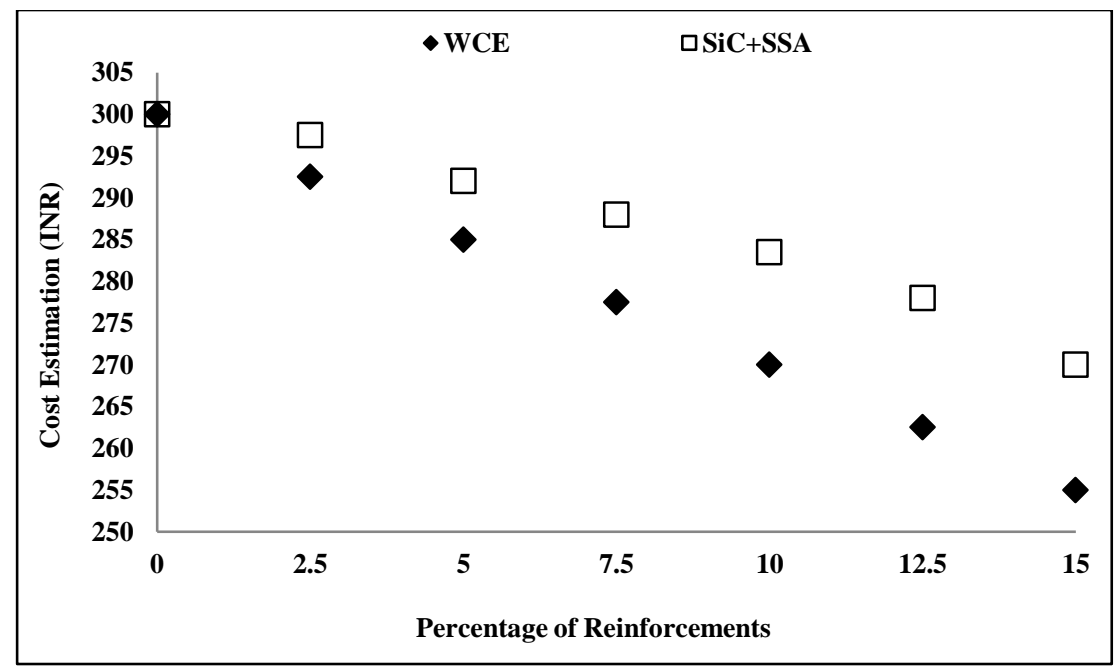

Figure 3. Cost estimation 
International Journal of Mathematical, Engineering and Management Sciences

Vol. 5, No. 3, 556-566, 2020

https://doi.org/10.33889/IJMEMS.2020.5.3.046

\section{Conclusion}

Recycling is the most important criterion which is the prime concern in this paper to fabricate green aluminum matrix composite for environmental sustainability. In this paper, ARAS, MABAC, COPRAS and MOOSRA are used for the selection of best material which is A24. Sample number 3 proved to be the best sample after all the experimentation of the 25 samples. There is a high dependency of the tribo-mechanical properties on the fabricated hybrid samples which exactly matches with the past research works. Waste carbonized eggshells and eggshells prove to be the better reinforcements with the aluminum for obtaining the novel hybrid composite which has better characteristics than the monolithic alloy and other reinforced hybrid composites as discussed in this paper. The overall cost of WCE is found to be much cheaper than the other hybrid composites with better performance, hence concluding the feasibility of this developed novel hybrid WCE composite. This paper abridges the essential aspects of energy based MCDM methods and delineates various performance indicators for sustainable clean and renewable energy recovery.

\section{Conflict of Interest}

The authors confirm and declare that there is no conflict of interest for this publication.

\section{Acknowledgements}

The authors would like to express their sincere gratitude and thanks to the editor and all the anonymous reviewers for their busy time and valuable suggestions.

\section{References}

Adali, E.A., \& Işik, A.T. (2017). The multi-objective decision making methods based on MULTIMOORA and MOOSRA for the laptop selection problem. Journal of Industrial Engineering International, 13(2), 229-237.

Biswas, T.K., \& Das, M.C. (2018). Selection of hybrid vehicle for green environment using multiattributive border approximation area comparison method. Management Science Letters, 8(2), 121130 .

Bose, S., Pandey, A., \& Mondal, A. (2018). Comparative analysis on aluminum-silicon carbide hybrid green metal matrix composite materials using waste egg shells and snail shell ash as reinforcements. Materials Today: Proceedings, 5(14), 27757-27766.

Bose, S., Pandey, A., Mondal, A., \& Mondal, P. (2019). A novel approach in developing aluminum hybrid green metal matrix composite material using waste eggshells, cow dung ash, snail shell ash and boron carbide as reinforcements. In: Shanker, K., Shankar, R., Sindhwani, R. (eds) Advances in Industrial and Production Engineering (pp. 551-562). Springer, Singapore.

Chatterjee, P., \& Chakraborty, S. (2013). Gear material selection using complex proportional assessment and additive ratio assessment-based approaches: a comparative study. International Journal of Materials Science and Engineering, 1(2), 104-111.

Chatterjee, P., Athawale, V.M., \& Chakraborty, S. (2011). Materials selection using complex proportional assessment and evaluation of mixed data methods. Materials \& Design, 32(2), 851-860. 
International Journal of Mathematical, Engineering and Management Sciences

Vol. 5, No. 3, 556-566, 2020

https://doi.org/10.33889/IJMEMS.2020.5.3.046

Deep, G., Idrisi, A.H., \& Siddiqui, T.U. (2016). Investigation and analysis for mechanical properties of aluminium silicon carbide composite. International Journal of Innovative Research in Science, Engineering and Technology, 5(9), 16720-16725.

Hassan, S.B., \& Aigbodion, V.S. (2015). Effects of eggshell on the microstructures and properties of Al$\mathrm{Cu}-\mathrm{Mg} / \mathrm{egg}$ shell particulate composites. Journal of King Saud University-Engineering Sciences, 27(1), 49-56.

Maity, S.R., Chatterjee, P., \& Chakraborty, S. (2012). Cutting tool material selection using grey complex proportional assessment method. Materials \& Design, 36, 372-378.

Pamučar, D., \& Ćirović, G. (2015). The selection of transport and handling resources in logistics centers using multi-attributive border approximation area comparison (MABAC). Expert Systems with Applications, 42(6), 3016-3028.

Popović, G., Stanujkić, D., \& Stojanović, S. (2012). Investment project selection by applying COPRAS method and imprecise data. Serbian Journal of Management, 7(2), 257-269.

Sarkar, A., Panja, S.C., Das, D., \& Sarkar, B. (2015). Developing an efficient decision support system for non-traditional machine selection: an application of MOORA and MOOSRA. Production and Manufacturing Research, 3(1), 324-342.

Xue, Y.X., You, J.X., Lai, X.D., \& Liu, H.C. (2016). An interval-valued intuitionistic fuzzy MABAC approach for material selection with incomplete weight information. Applied Soft Computing, 38, 703713.

Zavadskas, E.K., \& Turskis, Z. (2010). A new additive ratio assessment (ARAS) method in multicriteria decision-making. Technological and Economic Development of Economy, Baltic Journal on Sustainability, 16(2), 159-172. 